\title{
MOVEMENT OF GRAIN BOUNDARY IN SEA ICE
}

\author{
by
}

\section{TOSHIYUKI KAWAMURA}

Sea Ice Research Laboratory, Institute of Low Temperature Science, Hokkaido University, Mombetsu, Japan

\section{ABSTRACT}

An experimental study on the preferred growth of grains in sea ice was performed. As a seed an artificial bi-crystal was prepared by welding two single crystals; the c-axis of one grain was in a horizontal plane, that of the other made an angle of $\alpha$ with the horizontal plane, and they intersected at right angles. An angle between a resulting grain boundary and the vertical line, $\theta$, was measured on thin sections of sea ice after it grew about 10 $\mathrm{cm}$ downward in sea water. The relation between $\alpha$ and $\theta$ was given by $\theta=0.4 \alpha+6$, when $\alpha$ was varied from $-25^{\circ}$ to $25^{\circ}$. When $\alpha=0^{\circ}$, that is c-axes of both the grains are at right angles on a horizontal plane, encroachment still occurs, which is contrary to the earlier studies. These results can be explained by the difference in the horizontal component of growth rate between neighbouring grains at the grain boundary groove.

\section{INTRODUCTION}

Grains of sea ice with their c-axes closely horizontal grow preferentially at the cost of other grains. Perey and Pounder (1958) have explained this preference by assuming that growth rate in the basal planes is greater than that in the direction normal to them. Ketcham and Hobbs (1967) have ascribed the appearance of preferred orientations to the asymmetrical shape of growth at grain boundaries. Their theory, however, was prepared only to explain the restrictive cases of crystallographic arrangements. Ramseier (1968) has reported a more general rule that the preferred growth proceeds depending on the sum of the crystallographic components in the growth direction.

Recently, however, Kawamura (1982) made a careful observation of horizontal slices of natural sea ice and found that grains with their c-axes lying in a horizontal plane still encroach on each other. This result can not be explained by the above theories. This paper confirms experimentally the field observations and examines the dependence of encroachment on the relation between c-axes of neighbouring grains. Since arrangements of crystal axes of adjacent grains are generally complex in natural sea ice, an artificial bi-crystal was used in this study.

\section{EXPERIMENT}

An artificial bi-crystal was prepared by welding two pure single ice crystals, $2.5 \mathrm{~cm}$ by $4 \mathrm{~cm}$ in area and 0.7 $\mathrm{cm}$ thick, and was used as a seed for growth. A polyethylene tank $50 \mathrm{~cm}$ upper diameter, $42 \mathrm{~cm}$ lower diameter and $85 \mathrm{~cm}$ high, was filled with sea water with salinities about 32,16 and $7 \%$ by weight. Growth proceeded downward, its growth rate was kept constant by controlling the surrounding temperature, and varied from 0.2 to $2.0 \mathrm{~mm} / \mathrm{h}$. After about $10 \mathrm{~cm}$ thick growth, sea ice was removed from the tank and cut into thin sections. Observations of vertical and horizontal sections gave encroachment angles of grain boundaries. The crystal axes of bi-crystals were determined from X-ray Laue photographs.

\section{RESULTS AND DISCUSSION}

A horizontal thin section (Figure 1) shows that the middle grain was wedged out by adjacent grains. Since encroachment occurred more predominantly in the centra part of a grain boundary, it was measured there. A vertical

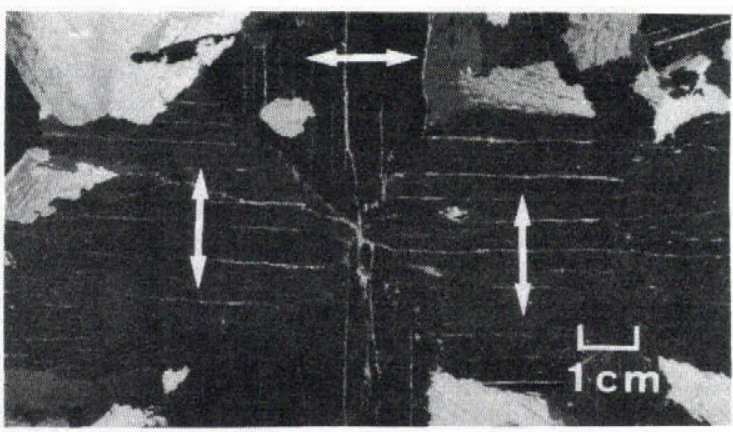

Fig.1. Horizontal thin-section photograph of sea ice at a depth of $7.0 \mathrm{~cm}$. Arrows represent c-axes of the grains. The middle grain was wedged out by grains on either side.

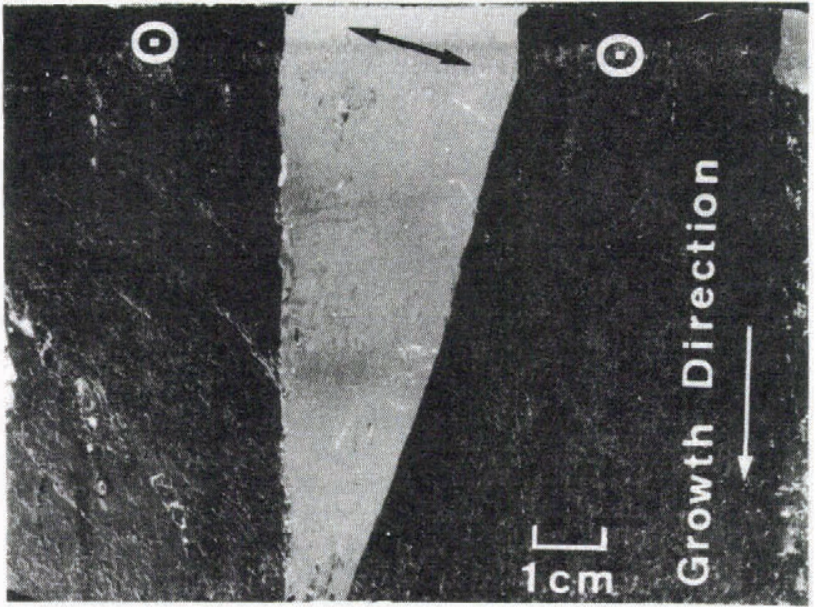

Fig.2. Vertical thin section at maximum encroachment. Arrow and circles with dot represent c-axes of the grains. The c-axis of the middle grain was inclined at $18^{\circ}$ to the horizontal plane.

thin section (Figure 2) shows that the grain boundary is almost straight, though with some irregularities.

Figure 3 illustrates schematically the arrangement of grains and definition of angles. The $\mathrm{c}$-axis of one grain (grain A) is inclined at an angle of $\alpha$ to the horizontal plane and its projection onto the horizontal plane is perpendicular to the initial welding grain boundary. Angle $\alpha$ can also be regarded as the angle between the basal plane of grain $A$ and the vertical line. On the contrary, the direction of the c-axis of the other grain (grain B) is horizontal and also parallel to the grain boundary. One a-axis was directed horizontally in both $A$ and $B$. The encroachment angle $\theta$ was defined as the angle between the resulting grain boundary and the vertical line. Signs of $\alpha$ and $\theta$ were taken as shown in the figure. In this study, $\alpha$ 


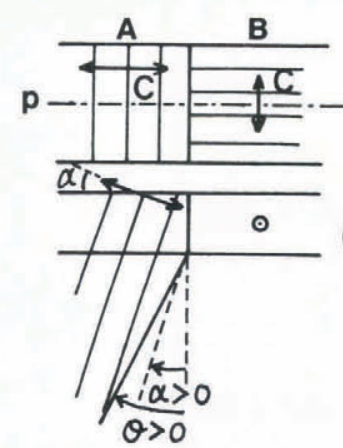

(a)

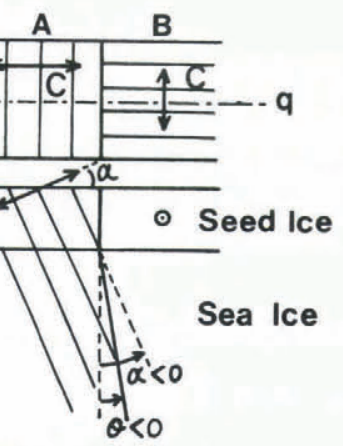

Fig.3. Schematical arrangement of the seed bi-crystal. (a) plan view, (b) cross-sectional view of line $p-q$ in (a).

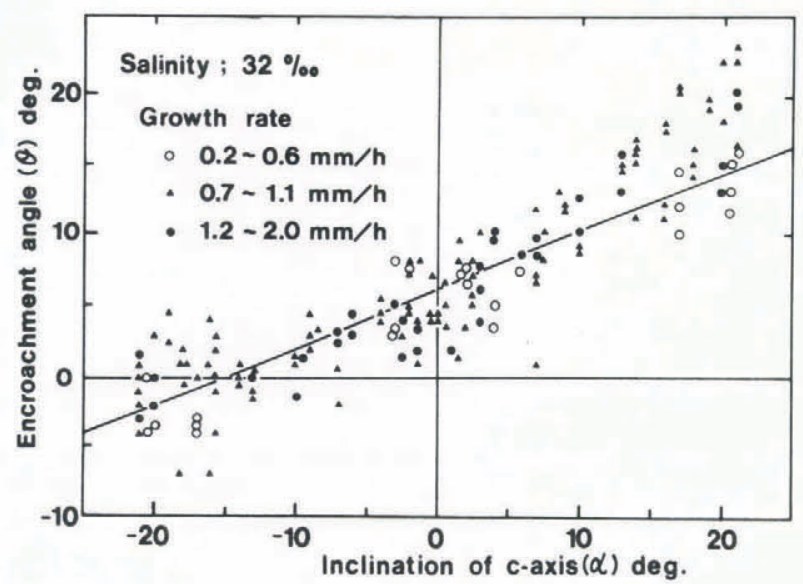

Fig.4. Relation between $\alpha$ and $\Theta$. Salinity: $32 \%$. Straight line represents $\theta=0.4 \alpha+6$.

was altered between $\pm 25^{\circ}$ and the direction of the c-axis of grain B was not changed.

Figure 4 gives the result obtained at salinity of $32 \%$. It shows that the relation between $\alpha$ and $\theta$ is linear regardless of growth rate and is given by

$$
\theta=0.4 \alpha+6
$$

Similar results are found at salinities 16 and $7 \%$. It can be concluded that neither salinity nor growth rate are important in determining the relation between $\alpha$ and $\theta$ in growth.

According to our experimental result, expressed as Equation (1), wedging-out still occurs even when $\alpha=0^{\circ}$; grain B encroached on grain A. The result is contradictory to the general rule given by Ramseier (1968), which predicts that grains A and B do not encroach on each other since the sums of their crystallographic components are the same. To explain the above result, we point out the importance of difference in the horizontal component of growth rate between neighboring grains at the grain boundary groove. The lateral growth rate of grain $B$ is greater than that of $\mathrm{A}$ at the grain boundary groove, since the growing surface of grain $A$ is near the closest-packed basal plane which has the smallest growth rate (Fletcher 1970). Therefore the grain boundary is expected to move toward grain $\mathrm{A}$, and grain $\mathrm{A}$ will be wedged out.

\section{ACKNOWLEDGEMENTS}

I thank Professor N Ono and Professor N Maeno of Hokkaido University for their valuable suggestions and encouragement throughout this study.

\section{REFERENCES}

Kawamura T 1982 [Measurements of crystallographic orientations of sea ice]. Low Temperature Science A(41): 173-178
Ketham W M, Hobbs P V 1967 The preferred orientation in the growth of ice from the melt. Journal of Crystal Growth 1: 263-270

Fletcher N H 1970 The chemical physics of ice Cambridge, Cambridge University Press

Perey F G J, Pounder E R 1958 Crystal orientation in ice sheets. Canadian Journal of Physics 36: 494-502

Ramseier R O 1968 Origin of preferred orientation in columnar ice. Journal of Crystal Growth 3(4): 621-624 